\title{
Strengthening interfaces between biaxial oriented PET and PSMA: Effects of nitrogen plasma and bonding treatments
}

\author{
Chi-An Dai ${ }^{\text {a,b,c, } *}$, Yi-Huan Lee ${ }^{\text {b }}$, Ai-Chien Chiu ${ }^{\text {c }}$, Tai-An Tsui ${ }^{\text {a }}$, Keng-Jen Lin ${ }^{\text {b }}$, \\ Kai-Ling Chen ${ }^{\text {a }}$, Ming-Wei Liu ${ }^{\text {d,e }}$ \\ ${ }^{a}$ Department of Chemical Engineering, National Taiwan University, No. 1 Roosevelt Rd., Sec. 4, Taipei 106, Taiwan \\ ${ }^{\mathrm{b}}$ Institute of Polymer Science and Engineering, National Taiwan University, Taipei 106, Taiwan \\ ${ }^{\mathrm{c}}$ Department of Physics, National Taiwan University, Taipei 106, Taiwan \\ ${ }^{\mathrm{d}}$ Institute of Biomedical Engineering, National Taiwan University, Taipei 106, Taiwan \\ e Taiwan Adventist Hospital, Taipei 105, Taiwan
}

Received 8 January 2006; received in revised form 14 September 2006; accepted 24 September 2006

Available online 14 November 2006

\begin{abstract}
The fracture toughness, $G_{\mathrm{c}}$, of the interface between a nitrogen plasma-treated poly(ethylene terephthalate) (PET) film and a poly(styreneco-maleic anhydride) (PSMA) substrate was measured by using asymmetric double cantilever beam method. The effects of plasma treatment condition on PET films and post-plasma bonding treatment of the bi-material on the adhesion and the failure mechanism were investigated. For a given plasma pressure and energy, the amount of incorporated nitrogen on the PET surface as determined from X-ray photoelectron spectrometry (XPS) increased with increasing plasma treatment time and reached a plateau value of 7.7 at.\%. XPS measurement showed that the incorporated nitrogen was primarily in the form of amine and amide. For bonding temperatures between $130{ }^{\circ} \mathrm{C}$ and $160{ }^{\circ} \mathrm{C}$, the fracture toughness increased with increasing nitrogen incorporation on PET surface and reached a saturation $G_{\mathrm{c}}$ which significantly depended on the bonding temperature. The saturation $G_{\mathrm{c}}$ increased from $10 \mathrm{~J} / \mathrm{m}^{2}$ at $130{ }^{\circ} \mathrm{C}$ to $40 \mathrm{~J} / \mathrm{m}^{2}$ at $140{ }^{\circ} \mathrm{C}$, reached a maximum of $120 \mathrm{~J} / \mathrm{m}^{2}$ at $150{ }^{\circ} \mathrm{C}$, and then decreased to $60 \mathrm{~J} / \mathrm{m}^{2}$ at $160^{\circ} \mathrm{C}$. The location of failure also changed drastically with the bonding temperature. SEM and XPS measurements showed that for bonding temperature $<140{ }^{\circ} \mathrm{C}$, failure occurred at the PET/PSMA interface. For bonding temperature $=150{ }^{\circ} \mathrm{C}$, the interfacial adhesion exceeded that of the cohesive strength of PET film and failure occurred within the PET film. At the bonding temperature of $160{ }^{\circ} \mathrm{C}$, failure occurred within PSMA bulk material. XPS measurement was used to measure the areal joint density, $\Sigma_{\text {cross }}$ of PSMA chains pinned on the functionalized PET film surface. A transition in areal joint density below which $G_{\mathrm{c}}$ scales linear with $\Sigma_{\text {cross }}$ and above which $G_{\mathrm{c}}$ scales with $\Sigma_{\text {cross }}^{2}$ was found. The transition was identified as the transition from the pure chain scission of in situ formed copolymers to plastic deformation of the interface.
\end{abstract}

(C) 2006 Elsevier Ltd. All rights reserved.

Keywords: Fracture toughness; Biaxially oriented poly(ethylene terephthalate); Plasma treatment

\section{Introduction}

The adhesion of polymer interfaces plays a vital role in many commercial products ranging from multiphase polymer alloys, multilayer coatings, and multicomponent devices like semiconductor and optoelectronic devices [1]. However,

\footnotetext{
* Corresponding author. Department of Chemical Engineering, National Taiwan University, No. 1 Roosevelt Rd., Sec. 4, Taipei 106, Taiwan. Tel.: +886 2 33663051; fax: +886223623040.

E-mail address: polymer@ntu.edu.tw (C.-A. Dai).
}

chemically different polymers are normally not miscible due to very low entropy of mixing between such large molecules [2-5]. Interface between immiscible homopolymers is normally very weak but may be markedly strengthened by adding small amounts of block copolymer or random copolymers [6,7]. Another strategy in improving the adhesion between polymer blends or films is to produce chemical reaction of polymer chains at interfaces where in situ copolymers are formed [8-13]. Such a method is also known as reactive compatibilization which has become increasingly important since many new functionalized polymers and new processes [14] 
are now available and the functionality in the polymers can be easily incorporated during the manufacturing process.

However, to improve the adhesion of semicrystalline polymers is challenging. The crystallinity that gives many semicrystalline polymers their modulus and toughness complicates the promotion of adhesion when joined with other polymers. A classical example is poly(ethylene terephthalate) (PET) which is widely used as film, fiber or bottle [15]. Commercial PET flat films are formed by melt extrusion, biaxial drawing and heat treatment processes [16]. High crystallinity is resulted due to molecular alignment and strain-induced crystallization of PET during the stretching processes [17]. Because of its superb properties including thermal property, mechanical property, transparency, gas barrier and inertness toward chemicals, PET is used as a leading substrate material for applications in coating, packaging, electronic, and biomedical industries [18]. In the area of biomedical application, PET has been used as a substrate material for prosthetic heart valves and vascular grafts $[19,20]$. In order to improve the biocompatibility of PET film substrate, surface treatments or coatings are needed [21]. However, the interface between PET film and coatings is rather weak because of its high crystallinity and inertness toward chemicals. Therefore, finding a solution to improve the interfacial adhesion between two incompatible polymers in which at least one of the polymers is semicrystalline is a critical issue and an actively researched topic.

To overcome the above mentioned problem, surface energetic treatment such as corona discharge or plasma treatment has been widely used and proven to be an effective method to modify surface's reactivity to depths of a few molecular layers without affecting the bulk properties [22]. Although large body of literature in the past has studied the effect of plasma treatment on the surface composition change of many commercial plastic films [23-28], a direct relationship between the surface chemistry and the adhesion strength has not been fully exploited. Many conventional methods used to measure interfacial adhesion between two bulk materials e.g. peel test, wedge test, etc. give only qualitative information on adhesion. There are great demands to explore new methods for measuring thin film adhesion.

In this paper, we will present a strategy for preparing reactive nitrogen-containing PET surfaces, using the methods of plasma treatment. Firstly, we will show that the ratios of surface functionalization, which depend on the selected plasma conditions, are further enhanced by post-plasma heat treatment of the bi-material. In situ copolymer formation is expected to occur by reaction of the nitrogen-containing functional groups on PET surface generated by plasma treatment with an anhydride group on the PSMA to first form an amic acid followed by ring closure to form an imide [29]. Secondly, we will establish a direct quantitative correlation between the surface chemistry created by plasma treatment and the adhesion strength of the interface. In addition, the mechanical and thermal properties of commercial PET films depend strongly on their manufacturing process [16]. During the drawing and heat processes, substantial increase in crystallinity and preferential chain orientation parallel to PET film surface were resulted, which lead to anisotropy in its mechanical property [3032]. It is well known that if the crystals are too highly ordered parallel to the surface with too few tie-molecules binding them in the bulk, then the surface crystal may delaminate under stress [33]. However, a quantitative failure criterion for interlayer delamination was not previously established. Thirdly, we will show that by using the sample preparation method and the quantitative adhesion measurement used in this study, such criterion is established.

\section{Experimental section}

\subsection{Materials}

The $100 \mu \mathrm{m}$-thick poly(ethylene terephthalate) films used in this study were sequentially biaxially oriented untreated PET film purchased from the Shin-Kong Synthetic Fibers Corporation, Taiwan. A small piece of PET film with dimension $6 \mathrm{~cm} \times 6 \mathrm{~cm}$ was cut from the center portion of the polymer web in a roll of $1 \mathrm{~m}$ in width. Prior to plasma treatment, the cut PET film was cleaned by rinsing with distilled water and methanol and then in refluxing hexane for $2 \mathrm{~h}$. Poly(styreneco-maleic anhydride) (PSMA) is a random copolymer with $93 \mathrm{wt} \%$ of styrene and $7 \mathrm{wt} \%$ of anhydride units purchased from Aldrich Chemical Company. The weight-average molecular weight of PSMA is $\sim 220,000$ as measured by gel permeation chromatography (GPC) and its glass transition temperature is $\sim 120^{\circ} \mathrm{C}$ as measured by differential scanning calorimetry.

\subsection{Plasma treatment of PET}

All PET films were plasma treated using a radio-frequency $(13.56 \mathrm{MHz})$ power source and a matching impedance unit at a nitrogen pressure of 200 mtorr and an output power of $40 \mathrm{~W}$. We varied the duration of the plasma treatment from 0 to $400 \mathrm{~s}$ to enhance the amount of nitrogen incorporated on PET surface. The high voltage electrode was fabricated from titanium metal and the ground aluminum electrode is the vacuum chamber itself. PET film samples were placed on a sample plate, which was located between the high voltage electrode and the ground electrode. The electrode and sample plate geometry provide greater uniformity for the treated surface of the samples as verified by the contact angle measurement (result not shown).

\subsection{Surface analysis}

Once the PET film is plasma treated, the film is quickly transferred into the chamber of X-ray photoelectron spectroscopy for the measurement of chemical composition of the treated surfaces. The XPS spectra were acquired on a VG Scientific ESCALAB 250 photoelectron spectrometer with monochromatic $\mathrm{Mg} \mathrm{K} \alpha$ X-rays $(1253.6 \mathrm{eV})$. All spectra were referenced to the $\mathrm{C} 1 \mathrm{~s}$ peak of the aliphatic carbon atoms, which was assigned a value of $284.6 \mathrm{eV}$. Spectra were taken at a $45^{\circ}$ electron takeoff angle which roughly corresponds to an 
analysis depth of $5 \mathrm{~nm}$ [22]. For the high-resolution spectra, the full width at half maximum (FWHM) for the individual components of the $\mathrm{C} 1 \mathrm{~s}$ peak in an untreated PET sample varies from 1.0 to $1.2 \mathrm{eV}$. The line-shape analysis is done using a non-linear least squares curve-fitting routine employing line shapes with $90 \%$ Gaussian and 10\% Lorentzian character. To determine the chemical composition of the treated surfaces, a self-consistent method is used by examining both survey scan spectra and the high-resolution spectra iteratively for each plasma treatment condition.

\subsection{Sample preparation}

Plates of PSMA of $1.5 \mathrm{~mm}$ in thickness were made by compression molding at $160^{\circ} \mathrm{C}$. After PET films were plasma treated, the film was immediately placed on a PSMA plate surface and the bi-material was placed in a compression mold under a slight pressure and annealed to enhance the bonding between PET and PSMA at five different temperatures of $120{ }^{\circ} \mathrm{C}, 130{ }^{\circ} \mathrm{C}, 140{ }^{\circ} \mathrm{C}, 150{ }^{\circ} \mathrm{C}$ and $160{ }^{\circ} \mathrm{C}$ for $2 \mathrm{~h}$. The bonding is expected to occur by reaction of the amine groups generated from plasma treatment on PET surface with an anhydride group on the PSMA to first form an amic acid followed by ring closure to form an imide [29,34]. Since the asymmetric double cantilever beam test (ADCB) requires that the materials on both side of the interface be elastic beams, PET film alone bonded on a PSMA plate is not suitable for the test. The problem was avoided by backing the PET film with a thick poly(methyl methacrylate) slab (thickness in the range of $1-3 \mathrm{~mm}$ ) using a commercial cyanoacrylate glue to adhere PMMA onto the backside of the PET film. The schematic of the sample assembly is shown in Fig. 1(a). After the fracture experiment, both sides of fracture surface were analyzed by using scanning electron microscopy and XPS measurement.

\subsection{Fracture toughness measurement}

The interfacial fracture toughness, $G_{\mathrm{c}}$ is measured using ADCB method as shown in Fig. 1(a). A razor blade of known thickness $\Delta$ is inserted into the PET/PSMA interface. A crack is initiated ahead of edge of the razor blade. This razor blade is driven by a servo motor at a constant speed $\left(5 \times 10^{-6} \mathrm{~m} / \mathrm{s}\right)$. Steady state crack propagation was established after several minutes. Based on Kanninen's calculation for a small crack in a biomaterial each with finite elasticity, the fracture toughness of the interface can be measured from the following equation [35]:

$G_{\mathrm{c}}=\frac{3 \Delta^{2}}{8 a^{4}}\left(E_{1} E_{2} h_{1}^{3} h_{2}^{3}\right) \frac{\left(C_{1}^{2} E_{2} h_{2}^{3}+C_{2}^{2} E_{1} h_{1}^{3}\right)}{\left(C_{1}^{3} E_{2} h_{2}^{3}+C_{2}^{3} E_{1} h_{1}^{3}\right)^{2}}$

where $C_{1}=1+0.64 h_{1} / a$ and $C_{2}=1+0.64 h_{2} / a . E_{1}$ and $E_{2}$ are the Young's moduli and $h_{1}(\sim 1.6 \mathrm{~mm})$ and $h_{2}(1-3 \mathrm{~mm})$ are the thicknesses of PSMA and PMMA beams, respectively. Since the backing PMMA beam $(\sim 1-3 \mathrm{~mm})$ for PET film

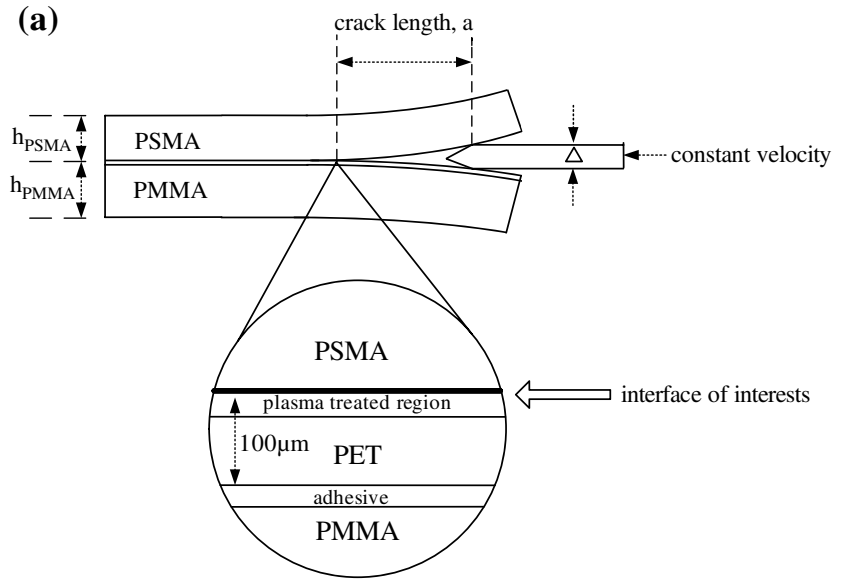

(b)

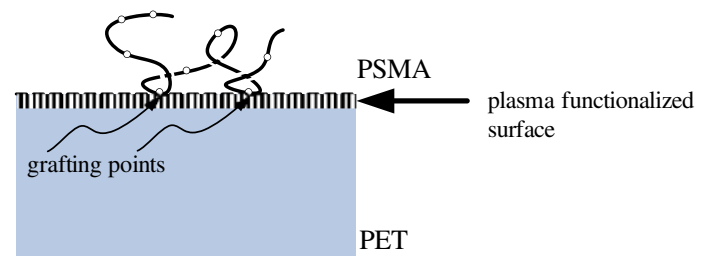

Fig. 1. (a) A schematic drawing of a PET/PSMA sample showing details of the sandwich structure (the enlarged circular drawing) and the asymmetric double cantilever beam method for fracture toughness measurement. (b) A schematic drawing of a PSMA chain forming a stitch structure on functionalized PET surface.

is much thicker than that of the PET film itself $(\sim 100 \mu \mathrm{m})$, the modulus of PET side of the beam is that of the PMMA slab. It is known now that as a crack propagates along an interface between two materials with different elastic moduli and thicknesses the stress field of the crack tip along the interface has both tensile $\left(K_{\mathrm{I}}\right)$ and shear $\left(K_{\mathrm{II}}\right)$ components, where $K_{\mathrm{I}}$ and $K_{\mathrm{II}}$ are the stress intensity factors corresponding to tensile and shear components of the stress along the crack [36]. A phase angle, $\Psi$ of an interface defined as

$\Psi=\tan ^{-1}\left(\frac{K_{\mathrm{II}}}{K_{\mathrm{I}}}\right)$

is a measure of the relative shear to tensile components. In general, the direction of crack deflection depends on the phase angle as well as the details of the failure and deformation mechanisms of the interface and those of the bulk materials above and below the interface. The effect of different thickness ratios of $h_{\mathrm{PMMA}}$ to $h_{\mathrm{PSMA}}$, therefore different phase angles, on the fracture toughness and failure mechanism of PET/PSMA sample will be studied in the following section.

\section{Results and discussion}

\subsection{XPS analysis of plasma-treated PET surface}

We have analyzed PET film surface plasma treated with nitrogen at a pressure of 200 mtorr and at a plasma power of 
$40 \mathrm{~W}$ for different amounts of treatment time. The XPS survey scan measurement gives the elemental composition of PET surface after the treatment as shown in Fig. 2(a). PET is initially free of nitrogen. With increasing treatment time, PET shows an increase in the amount of nitrogen incorporation at the surface as seen from the growth of $\mathrm{N} 1 \mathrm{~s}$ peak in Fig. 2(a). The integrated area under $\mathrm{C} 1 \mathrm{~s}, \mathrm{O} 1 \mathrm{~s}$ and $\mathrm{N} 1 \mathrm{~s}$ peaks, corrected for their ionization cross-sections, provides the relative atomic percentage of carbon, oxygen and incorporated nitrogen, respectively, on the treated PET surfaces. The atomic percentage of nitrogen incorporated on PET film surface is plotted as a function of plasma treatment time as shown in Fig. 2(b). The amount of nitrogen incorporation increases quickly with increasing treatment time and gradually reaches a saturation level of $\sim 7.7 \%$ for treatment time $\geq \sim 150 \mathrm{~s}$. XPS high-resolution spectra were also acquired to reveal the chemical structure produced as a result of exposure of the PET surface to the nitrogen plasma treatment. Although a variety of chemical species can be generated on polymer surface
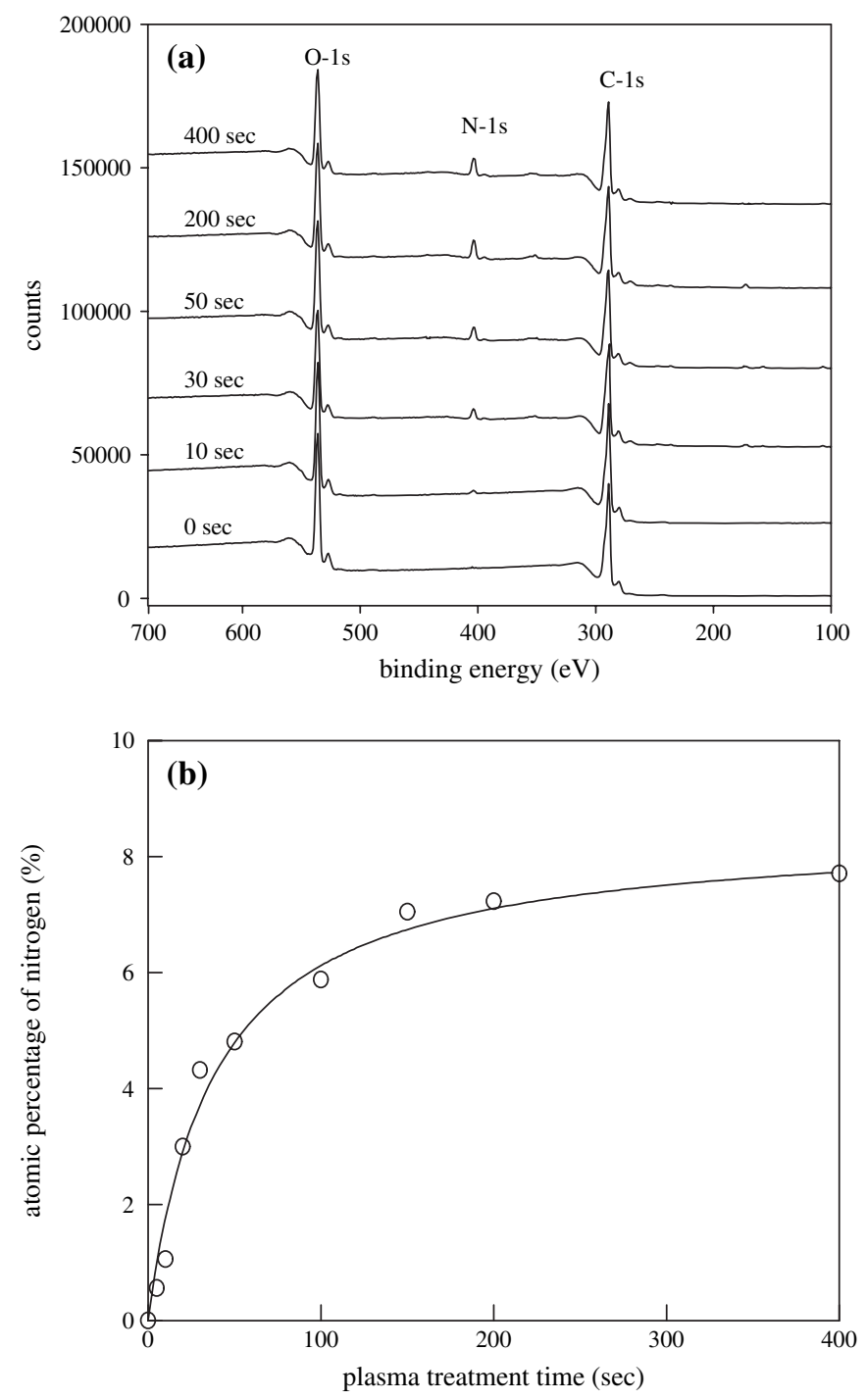

Fig. 2. (a) XPS survey scans for PET film treated with nitrogen plasma for different amounts of time. (b) The atomic percentage of incorporated nitrogen measured from XPS as a function of nitrogen plasma treatment time. by using plasma treatment. For example, it was previously shown that the oxygen-containing polymers treated with nitrogen plasma produce primarily amine, imine and amide functional groups [37]. Recently, Gerenser et al. used XPS as well as other complimentary surface techniques to thoroughly examine the chemical structure of poly(ethylene-2,6-naphthalate) (PEN), a close derivative polyester of PET, treated with nitrogen plasma treatment [22]. They found that the plasma treatment produces disruption of both the naphthalene rings and ester groups and generates mainly aliphatic-like species, amine and amide functional groups on the nitrogen plasmatreated PEN surface.

Fig. 3(a)-(c) shows the changes in the high-resolution $\mathrm{C} 1 \mathrm{~s}, \mathrm{O} 1 \mathrm{~s}$ and $\mathrm{N}$ 1s XPS spectra, respectively, after different treatment times of nitrogen plasma on PET surface. In Fig. 3(a), as the treatment time increases, there is significant line-broadening of the carbon spectra which indicates a disruption of long range order in the PET surface as more nitrogen incorporates onto the PET surface. Plasma treatment also causes line-broadening of oxygen high-resolution spectra. In addition, as the treatment time increases, the intensity of the ester-type oxygen $(\mathrm{C}-\mathrm{O})$ decreases relative to the carbonyltype oxygen $(\mathrm{C}=\mathrm{O})$. At longer treatment times (e.g. 150 and $300 \mathrm{~s}$ of treatment time), $\mathrm{C}-\mathrm{O}$ peak decreases significantly and $\mathrm{C}=\mathrm{O}$ peak becomes dominant. Therefore, for $\mathrm{O}$ 1s spectra of nitrogen plasma-treated PET, it suggests a disruption of ester functional groups with an increase in the amount of amide functional group as the treatment time increases. Examination of $\mathrm{N} 1 \mathrm{~s}$ spectra also gives evidence of formation of amine and amide functional groups on the nitrogen plasmatreated PET surface. The shift of $\mathrm{N}$ 1s centroid from $\sim 399.1 \mathrm{eV}$ to $\sim 399.9 \mathrm{eV}$ indicates a relative population change of chemical structure of PET surface from the amine-type nitrogen $(399.1 \mathrm{eV})$ to amide-type nitrogen $(399.9 \mathrm{eV})$ with increasing plasma treatment time. Although other functional groups (e.g. imine groups) can be generated from the nitrogen plasma treatment of PET, previous work of Gerenser et al. on nitrogen plasma-treated PEN indicates that the primary functional groups generated are amine and amide types [22]. Since the chemical and molecular structures of PET and PEN are very similar, we can expect similar functional groups to be generated under similar plasma treatment condition. Therefore, with increasing plasma treatment time, the amount of nitrogen incorporation primarily in the form of amine and amide functional groups increases on PET surfaces. The increase of functional groups created on the nitrogen plasma-treated PET surface can be used to react with PSMA substrates thus increasing the adhesion between originally inert PET film and PSMA substrate.

\subsection{Effect of thickness ratio $\left(h_{P M M A} / h_{P S M A}\right)$ on adhesion and failure location}

In order to measure the interfacial adhesion, one needs to ensure that the crack propagates at the bi-material interface. It has been previously studied that the thickness ratio of sample beams used in the asymmetric double cantilever beam test 

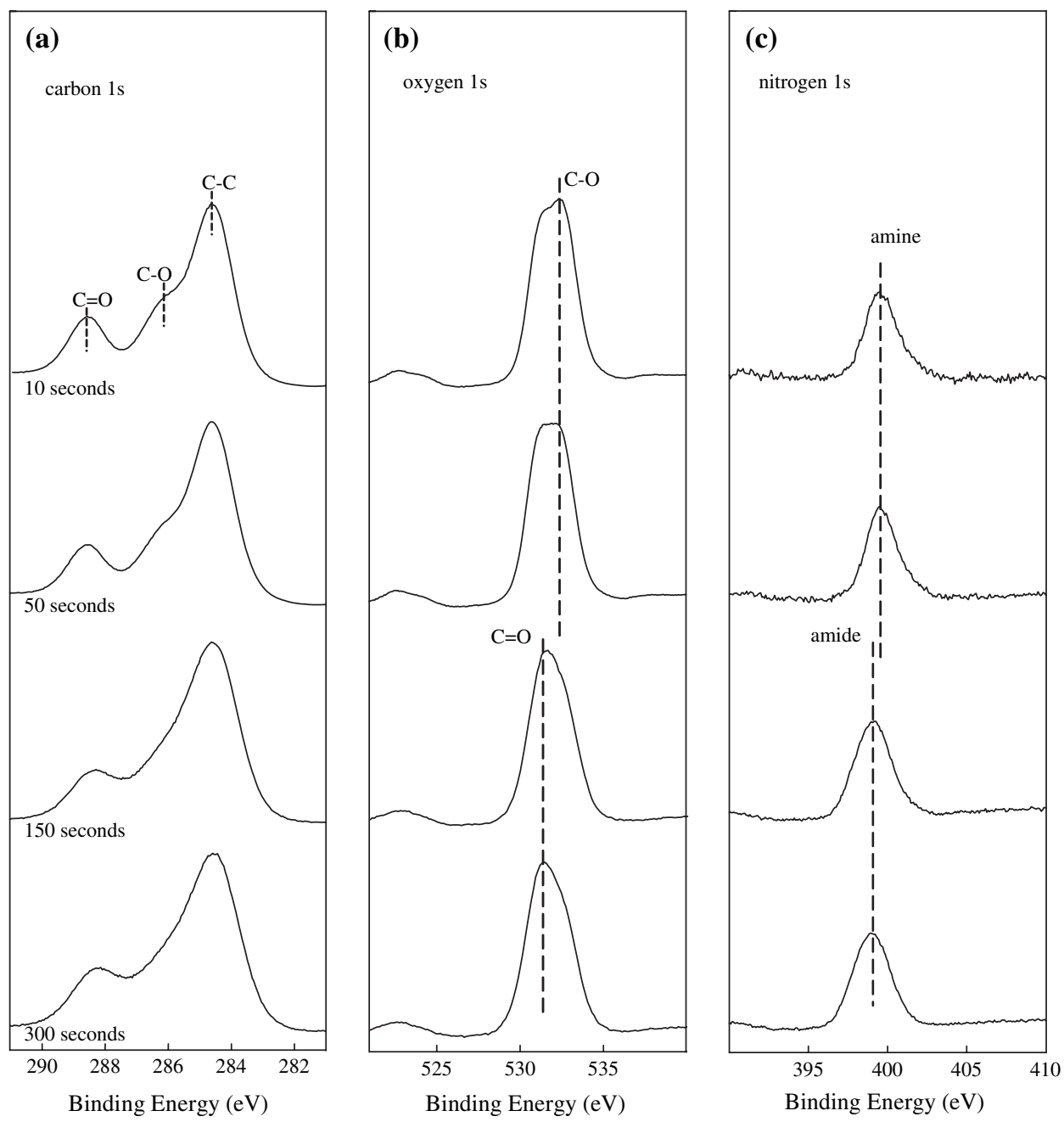

Fig. 3. XPS high resolution (a) $\mathrm{C} 1 \mathrm{~s}$, (b) $\mathrm{O} 1 \mathrm{~s}$, and (c) $\mathrm{N} 1 \mathrm{~s}$ spectra for nitrogen plasma-treated PET with different treatment times of 10, 50, 150 and $300 \mathrm{~s}$.

(ADCB) can significantly affect the stress intensity factor and the phase angle of the crack propagating at the interface [39]. Therefore, the effect of thickness ratios of the PSMA beam to the supporting PMMA substrate for PET on the adhesion and failure location needs to be thoroughly studied. As the thickness ratios are varied, the propensity to drive the crack into different locations in the sample is changed. The samples for the phase angle effect were prepared by treating PET films with nitrogen plasma at a pressure of 200 mtorr and output energy of $40 \mathrm{~W}$ for $30 \mathrm{~s}$ followed by annealing treatment of the PET/ PSMA bi-material at $150{ }^{\circ} \mathrm{C}$ for $2 \mathrm{~h}$. From Fig. 4, the fracture toughness of the samples was measured as a function of thickness ratio $\left(h_{\mathrm{PMMA}} / h_{\mathrm{PSMA}}\right)$. For $h_{\mathrm{PMMA}} / h_{\mathrm{PSMA}}>1.0$, the fracture toughness is relatively constant at a value of $50 \mathrm{~J} / \mathrm{m}^{2}$. However, for $h_{\mathrm{PMMA}} / h_{\mathrm{PSMA}}<1.0$, the fracture toughness increases dramatically to a value of $\sim 100 \mathrm{~J} / \mathrm{m}^{2}$. Scanning electron microscopic observations on the PET side of the fracture surface show that for $h_{\mathrm{PMMA}} / h_{\mathrm{PSMA}}<1.0$, the crack deviates from the PET/PSMA interface and propagates into the PET film, therefore resulting in a significant increase in the fracture toughness. However, when PMMA beam is made much thicker than the PSMA substrate $\left(h_{\mathrm{PMMA}} / h_{\mathrm{PSMA}}>1.8\right)$, the crack is likely driven more into the PSMA and subsequently the apparent adhesion is increased. For $h_{\mathrm{PMMA}} / h_{\mathrm{PSMA}} \sim 1.4$, there is a minimum in the fracture energy. Therefore, in order to measure a true interfacial fracture energy between PET/ PSMA and minimize bulk energy dissipation, we have chosen $h_{\mathrm{PMMA}} / h_{\mathrm{PSMA}}=1.4$ for all the samples tested by using asymmetric double cantilever beam method.

\subsection{Effect of bonding treatment time on PET/PSMA adhesion}

After PET films were plasma treated, the bonding between plasma-treated PET films and PSMA substrates was achieved by heating the PET/PSMA bi-material specimens in a compression mold at different temperatures for various amount of heat treatment time. The dependence of interfacial fracture toughness, $G_{\mathrm{c}}$ on the plasma treatment time for the PET/ PSMA adhesive joints annealed at $150{ }^{\circ} \mathrm{C}$ for different heat treatment times is shown in Fig. 5(a). For heat treatment time $=20 \mathrm{~min}$ and $2 \mathrm{~h}$, the fracture toughness increases with increasing plasma treatment time and then reaches a saturation value $G_{\mathrm{c}}^{*}$ at about $150 \mathrm{~s}$. For plasma treatment time $=200 \mathrm{~s}$, 


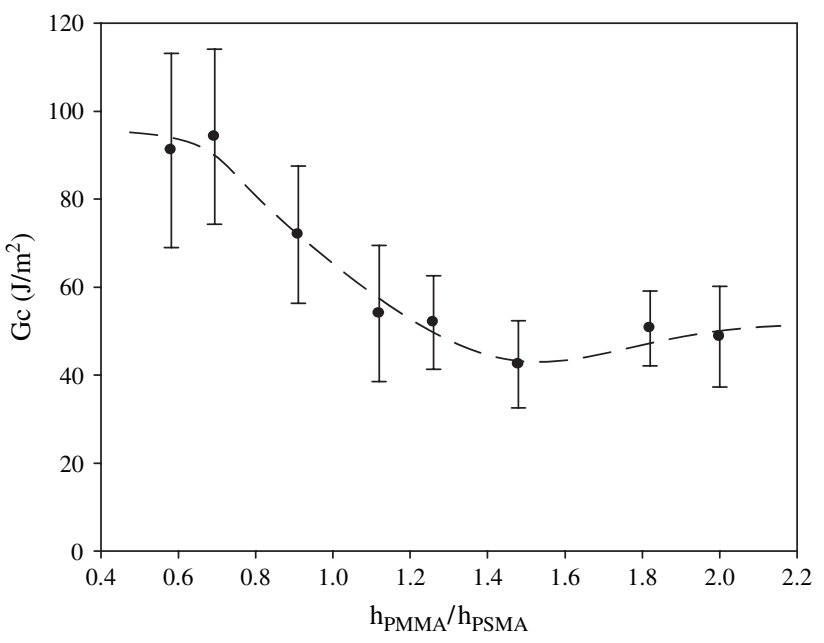

Fig. 4. Effect of thickness ratio $\left(h_{\mathrm{PMMA}} / h_{\mathrm{PSMA}}\right)$ of the elastic beam for ADCB test on the fracture toughness of PET/PSMA adhesive joints heat treated at $150{ }^{\circ} \mathrm{C}$ for $2 \mathrm{~h}$. The PET films used were plasma treated for $30 \mathrm{~s}$ prior to the heat treatment
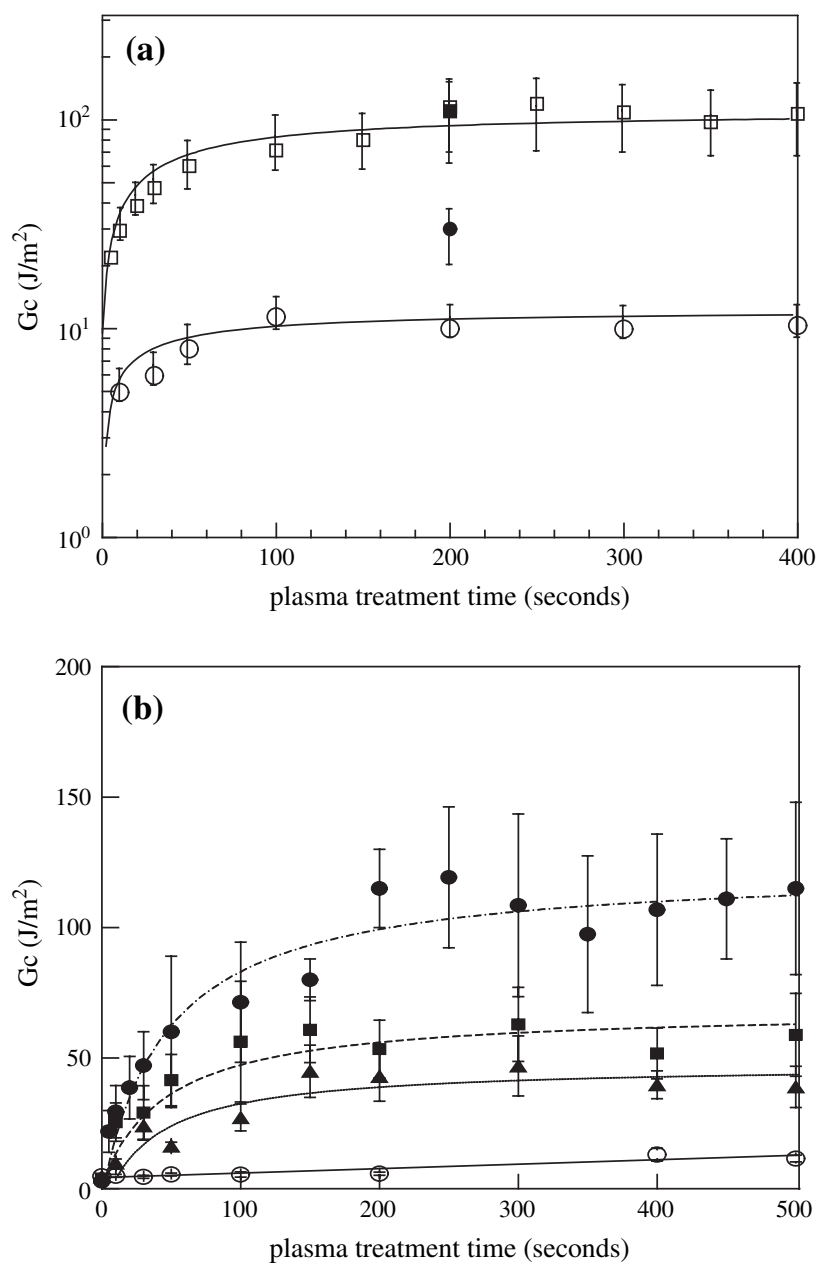

Fig. 5. (a) Effect of plasma treatment time on the fracture toughness of PET/ PSMA adhesive joints heat treated at $150^{\circ} \mathrm{C}$. ( $\bigcirc$ ) for $20 \mathrm{~min}$, (O) for $1 \mathrm{~h}$, ( $\square$ ) for $2 \mathrm{~h}$, and ( $\square$ ) for $4 \mathrm{~h}$. (b) Dependence of plasma treatment time on $G_{\mathrm{c}}$ for PET/PSMA heat treated at $(\mathrm{O},-) 130{ }^{\circ} \mathrm{C},(\boldsymbol{\Delta}, \ldots) 140{ }^{\circ} \mathrm{C},(\boldsymbol{O},-)$ $150{ }^{\circ} \mathrm{C}$ and $(\square,--) 160{ }^{\circ} \mathrm{C}$ for $2 \mathrm{~h}$. the fracture toughness of the interface for two additional heat treatment times $(1 \mathrm{~h}$ and $4 \mathrm{~h})$ is also included in Fig. 5(a). It is shown that with increasing heat treatment time, the $G_{\mathrm{c}}^{*}$ value increases and saturates for the heat treatment time $\geqq 2 \mathrm{~h}$. The above results show that for heat treatment time $<2 \mathrm{~h}$, the enhancement of interfacial adhesion is mainly due to the increase of areal density of in situ formed copolymers at the interface. For the heat treatment time $\geqq 2 \mathrm{~h}$, the areal chain density at the interface reaches its maximum. Based on the XPS analysis on the plasma-treated PET surface in the previous section, the total number of nitrogen incorporation on PET film increases with increasing plasma treatment time and saturates for treatment time $>150 \mathrm{~s}$. Although amine and amide groups are generated on PET films during plasma treatment, the amide functional groups do not react with maleic anhydride groups on PSMA within the experimental temperature range. Even for plasma treatment time $>150 \mathrm{~s}$, the number of amine functional groups appears to be sufficient to react with anhydride groups and forms in situ copolymers at the interface which enhance the adhesion. Since the fracture energy $G_{\mathrm{c}}^{*}$ saturates for heat treatment time $\geqq 2 \mathrm{~h}$, for the rest of this study post-heat treatment time of $2 \mathrm{~h}$ will be used.

\subsection{Effect of bonding treatment temperature on adhesion and failure location}

The effect of post-plasma heat treatment temperature on the PET/PSMA bi-material adhesion was studied. For the PET/PSMA adhesive joints annealed at a temperature less than $120^{\circ} \mathrm{C}$ for $2 \mathrm{~h}$, the glass transition temperature of PSMA, there was essentially no adhesion strength between all plasma-treated PET films and PSMA. Many PET/PSMA bi-material specimens annealed below $120^{\circ} \mathrm{C}$ cracked as soon as they were removed from the compression mold. For samples annealed at a temperature higher than $160^{\circ} \mathrm{C}$, it was found that the PET/PSMA adhesive joint was bent after annealing due to the mismatch of thermal expansion coefficient of the bi-materials. Therefore, for samples annealed at a temperature $>160^{\circ} \mathrm{C}$, an actuate $G_{\mathrm{c}}$ value could not be obtained without incorporating additional $G_{\mathrm{c}}$ contribution which takes into account the residual stress of the PET/PSMA bi-material assembly [40]. The $G_{\mathrm{c}}$ values and failure mechanisms of PET/PSMA bi-materials at high temperature annealing $\left(>160{ }^{\circ} \mathrm{C}\right)$ are not studied here.

As shown in Fig. 5(b), the fracture toughness of the PET/ PSMA interface is plotted as a function of plasma treatment time followed by annealing the PET/PSMA specimens at four different temperatures: $130{ }^{\circ} \mathrm{C}, 140{ }^{\circ} \mathrm{C}, 150{ }^{\circ} \mathrm{C}$, and $160{ }^{\circ} \mathrm{C}$ for $2 \mathrm{~h}$. For bonding temperature $=130{ }^{\circ} \mathrm{C}$, the $G_{\mathrm{c}}$ values do not increase much with increasing plasma treatment time. For bonding temperatures $=140^{\circ} \mathrm{C}, 150{ }^{\circ} \mathrm{C}$, and $160^{\circ} \mathrm{C}$, $G_{\mathrm{c}}$ increases significantly with the plasma treatment time and then saturates. The plasma treatment time at which $G_{\mathrm{c}}$ saturates increases weakly on the bonding temperature while the saturation value itself appears to be a very strong function of the bonding temperature. A striking feature of Fig. 5(b) is that the fracture toughness of the interface does not increase 
monotonically with increasing bonding temperature. As the bonding temperature increases from $140{ }^{\circ} \mathrm{C}$ to $150{ }^{\circ} \mathrm{C}$, the saturation fracture energy increases significantly from $\sim 40 \mathrm{~J} / \mathrm{m}^{2}$ to $\sim 110 \mathrm{~J} / \mathrm{m}^{2}$. However, as the bonding temperature increases from $150{ }^{\circ} \mathrm{C}$ to $160{ }^{\circ} \mathrm{C}$, the saturation fracture toughness, $G_{\mathrm{C}}^{*}$ decreases from $\sim 110 \mathrm{~J} / \mathrm{m}^{2}$ to $\sim 60 \mathrm{~J} / \mathrm{m}^{2}$.

The dramatic increases in the fracture toughness with increasing plasma treatment time correlate well with the amount of nitrogen incorporation with increasing plasma treatment time as shown in Fig. 2(b). Although, by treating PET film with nitrogen plasma a variety of carbon-nitrogen functional groups can be generated. However, based on our XPS measurement shown in Fig. 3, the incorporated nitrogen is mainly in the form of amine and amide functional groups. In addition, only amine functional groups are important for adhesion since amide functional groups do not react with anhydride groups at an appreciable rate under the current bonding temperature range [41]. Therefore, the dramatic increases in the fracture toughness of the interface as specimens annealed above $140{ }^{\circ} \mathrm{C}$ are resulted from the formation of chemical bonds formed by reaction of the amine functional group and anhydride functional groups at the interface thus generating in situ formed copolymers.

The locus of failure of the PET/PSMA adhesive joint was analyzed by various techniques such as scanning electron microscopy and XPS analysis. We first examine the location of failure of sample series of PET/PSMA adhesive joint with highest fracture energy at different plasma treatment times (bonding temperature $=150^{\circ} \mathrm{C}$ ). Fig. 6(a)-(d) shows SEM micrographs of the PET fracture surface of the adhesive joint prepared for plasma treatment of $10,50,150$ and $300 \mathrm{~s}$, respectively, and subsequently annealed at $150{ }^{\circ} \mathrm{C}$ for $2 \mathrm{~h}$. For plasma treatment time $=10 \mathrm{~s}$, the fracture surface of the PET film is relatively flat and the corresponding fracture toughness of the interface is relatively low $\left(G_{\mathrm{c}} \approx 25 \mathrm{~J} / \mathrm{m}^{2}\right)$. As the treatment time increases, plastic deformation of PET surface induced by the interfacial reaction was observed for treatment time $=50$ and $150 \mathrm{~s}$, which leads to a significant increase of energy dissipation. For treatment time $>300$ s, SEM micrograph shows a layered fracture surface morphology of PET film which indicates that the failure occurs within PET films. For treatment time $>200 \mathrm{~s}$, the fracture toughness of the PET/PSMA reaches its maximum and saturates at that annealing temperature.

The fracture surface of PET/PSMA adhesive joint was investigated by XPS in order to understand more precisely the path of the crack. The detected depth of XPS measurement was expected to be $\sim 5 \mathrm{~nm}$. Fig. 7(a) and (b) shows the XPS survey scans for the PET and PSMA fractured surface, respectively, of the PET/PSMA adhesive joint annealed for $2 \mathrm{~h}$ at $140{ }^{\circ} \mathrm{C}$. Since the monomer units for PET and PSMA have different number of carbon and oxygen atoms, we can use the relative peak ratio of carbon to oxygen in XPS measurements to distinguish the identity of the fracture surfaces. Fig. 7(a) and (b) shows that the relative peak ratio of carbon to oxygen of PET and PSMA sides of the fracture surface remains roughly the same with increasing plasma treatment time. With increasing plasma treatment time, most nitrogen remains on the PET side of the fracture surface and some nitrogen signals are shown on the PSMA side of the fracture
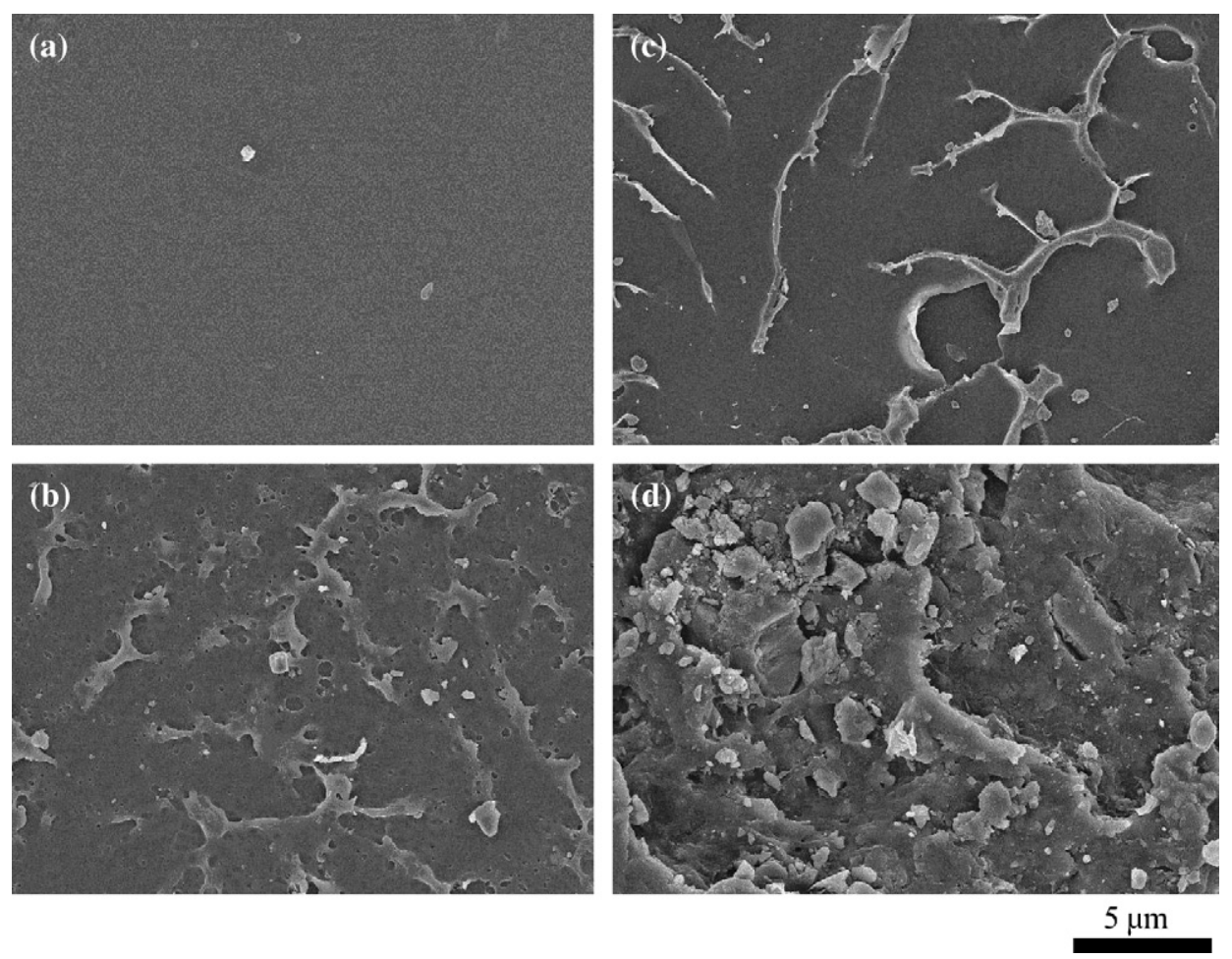

Fig. 6. SEM micrographs of fractured PET film after annealing with PSMA for $2 \mathrm{~h}$ at $150^{\circ} \mathrm{C}$ : (a) 10 , (b) 50 , (c) 150 and (d) $300 \mathrm{~s}$ of nitrogen plasma treatment at 200 mtorr pressure and at energy of $40 \mathrm{~W}$. 

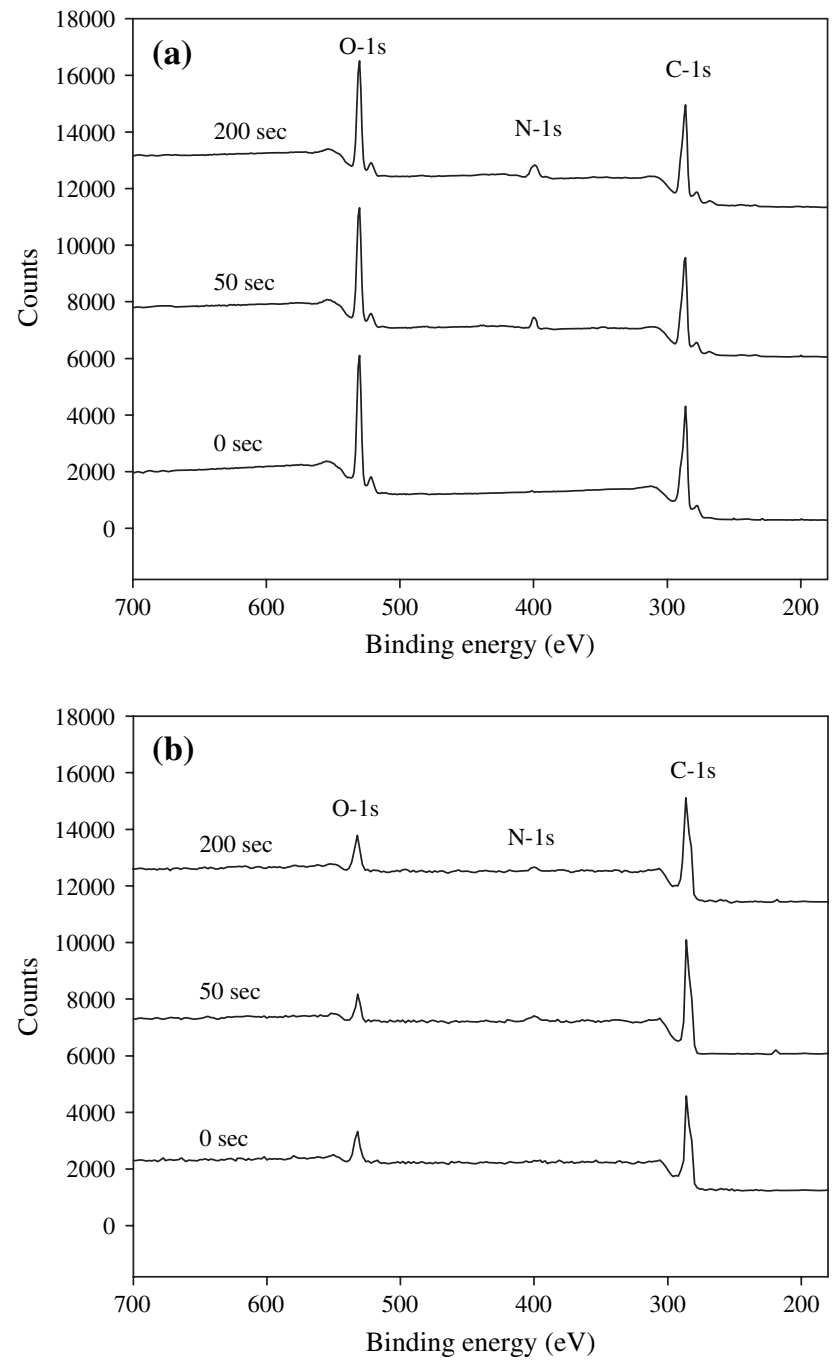

Fig. 7. XPS survey scans spectra for (a) PET side and (b) PSMA side of the fractured surface of the PET/PSMA adhesive joint annealed for $2 \mathrm{~h}$ at $140{ }^{\circ} \mathrm{C}$.

surface. It is therefore concluded that for the adhesive joints annealed at $140{ }^{\circ} \mathrm{C}$ for $2 \mathrm{~h}$, the fracture energy is low $\left(<40 \mathrm{~J} / \mathrm{m}^{2}\right)$ and the location of failure is right at the interface of PSMA substrate and plasma-treated PET film for all plasma treatment times. For the adhesive joints annealed at $130{ }^{\circ} \mathrm{C}$ for $2 \mathrm{~h}$, the fracture toughness is even lower than those annealed at $140{ }^{\circ} \mathrm{C}$ and the failure also occurs at the interface of PSMA substrates and PET films for all plasma treatment times.

However, a dramatically different failure mechanism is observed for the adhesive joint annealed above $140{ }^{\circ} \mathrm{C}$. Fig. 8(a) shows the XPS survey scan for the PSMA fracture surface of adhesive joints annealed at $150{ }^{\circ} \mathrm{C}$ for $2 \mathrm{~h}$ for different plasma treatment times. Fig. 8(a) shows that the relative peak ratio of carbon to oxygen changes with increasing plasma treatment time. With increasing plasma treatment time, the fracture toughness of the interface increases (from Fig. 5(b)) and Fig. 8(a) shows that the PSMA side of the fracture surface changes from a PSMA surface to a PET-like surface. In addition, as the PSMA side of the fracture surface becomes more PET-like, a nitrogen peak also starts to appear on the XPS
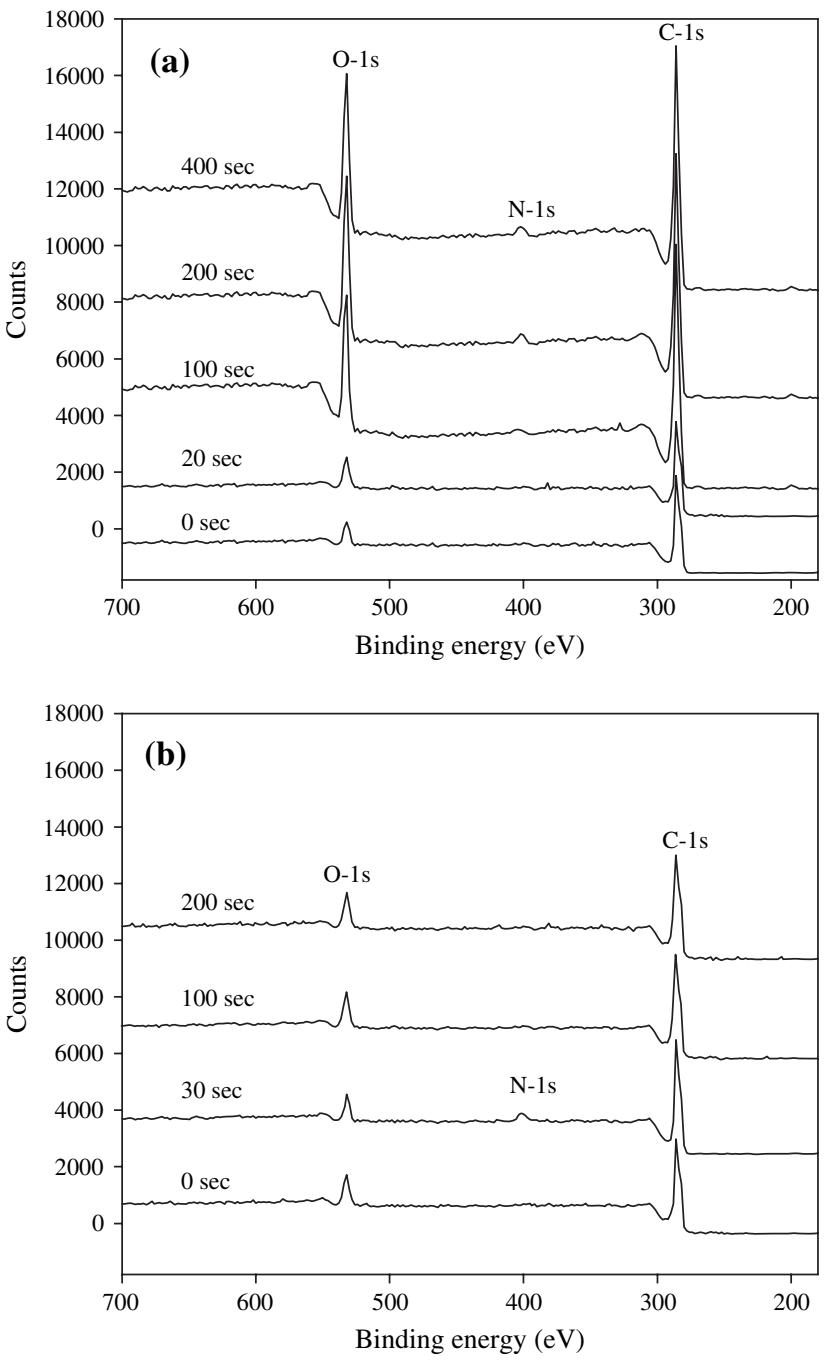

Fig. 8. XPS survey scans spectra for PSMA side of the fractured surface of the PET/PSMA adhesive joint annealed for $2 \mathrm{~h}$ at (a) $150{ }^{\circ} \mathrm{C}$ and (b) $160^{\circ} \mathrm{C}$.

survey scan spectra of the PSMA fracture surface for plasma treatment time $\geq 200 \mathrm{~s}$. The atomic percentage of carbon, oxygen and nitrogen of the PET side of the fracture surface for different plasma treatment times as measured from the XPS survey scan is tabulated in Table 1. For all plasma treatment times, the atomic percentage of carbon and oxygen on the PET fracture surface is close to that of carbon and oxygen on the pure PET surface as shown in Table 1. Based on the

Table 1

XPS analysis on the PET fracture surface of PET/PSMA adhesive joints annealed at $150^{\circ} \mathrm{C}$ for $2 \mathrm{~h}$

\begin{tabular}{llll}
\hline Plasma treatment time & \multicolumn{3}{l}{ Atomic percentage (at.\%) } \\
\cline { 2 - 4 } & $\mathrm{C}$ & $\mathrm{O}$ & $\mathrm{N}$ \\
\hline Pure PET & 72.5 & 28.8 & 0 \\
$20 \mathrm{~s}$ & 78.9 & 20.9 & 0.2 \\
$100 \mathrm{~s}$ & 82.3 & 17.4 & 0.3 \\
$200 \mathrm{~s}$ & 73.7 & 26.3 & 0 \\
$400 \mathrm{~s}$ & 72.7 & 27.3 & 0 \\
Pure PSMA & 90.6 & 9.36 & 0 \\
\hline
\end{tabular}


failure analysis on the PET and the PSMA side of the fracture surface as measured by using XPS technique and SEM morphology, it is clear that the location of failure of the adhesive joints annealed at $150{ }^{\circ} \mathrm{C}$ for $2 \mathrm{~h}$ is an interfacial failure between PET and PSMA for plasma treatment time $<200 \mathrm{~s}$. For plasma treatment time $\geq 200 \mathrm{~s}$, failure occurs inside the PET film near PET/PSMA interface. Therefore, both SEM micrographs (Fig. 7) and XPS results show that there is a change in the location of failure of the adhesive joint annealed at $150{ }^{\circ} \mathrm{C}$ with increasing plasma treatment time. For plasma treatment time $\geq 200 \mathrm{~s}$, the fracture toughness of the interface reaches a saturation value of $\sim 110 \mathrm{~J} / \mathrm{m}^{2}$. The change in the location of failure from interfacial failure to a bulk PET interlayer failure is therefore resulted from the fact that the fracture toughness of PET/PSMA exceeds that of the bulk PET interlayer strength. This is due to more in situ copolymer formation at the interface resulting from more amine functional groups generated on PET surface with increasing plasma treatment time.

For the adhesive joints annealed at $160^{\circ} \mathrm{C}$ for $2 \mathrm{~h}$, the saturation fracture toughness, $G_{\mathrm{c}}^{*}$ decreases dramatically from a maximum value of $\sim 110 \mathrm{~J} / \mathrm{m}^{2}$ at $150{ }^{\circ} \mathrm{C}$ to $\sim 60 \mathrm{~J} / \mathrm{m}^{2}$ at $160{ }^{\circ} \mathrm{C}$. Failure analysis was conducted on the fracture surface of the adhesive joints. Fig. 8(b) shows the XPS survey scan for the PSMA fracture surface of the adhesive joints annealed at $160{ }^{\circ} \mathrm{C}$ for $2 \mathrm{~h}$ for different plasma treatment times. With increasing plasma treatment time, the fracture toughness of the interface increases (Fig. 5(b)), however, the atomic ratio of carbon to oxygen of the PSMA side of the fracture surface does not change with increasing plasma treatment time which indicates that the location of failure is at the PSMA/PET interface or in the bulk PSMA. The atomic percentage of carbon, oxygen and nitrogen of the PET fracture surface for different plasma treatment times as measured from the XPS survey scan is tabulated in Table 2. For a pure PET film, the atomic percentage for carbon is nearly $73 \%$ while for pure PSMA, the atomic percentage is close to $90 \%$. With increasing plasma treatment time, the atomic percentage of carbon on the PET side of the fracture surface changes from that of a PET for plasma treatment time $<100 \mathrm{~s}$ to that of a PSMA for plasma treatment time $>100 \mathrm{~s}$. Therefore, based on the results from Fig. 9(b) and Table 2, we concluded that the location of failure changes from an interfacial failure between the PSMA/PET interface for low plasma treatment time ( $\lesssim 150 \mathrm{~s}$ ) to a bulk failure of PSMA for high plasma treatment time. This result

Table 2

XPS analysis on the PET fracture surface of PET/PSMA adhesive joints annealed at $160^{\circ} \mathrm{C}$ for $2 \mathrm{~h}$

\begin{tabular}{llll}
\hline Plasma treatment time & \multicolumn{3}{l}{ Atomic percentage (at.\%) } \\
\cline { 2 - 4 } & $\mathrm{C}$ & $\mathrm{O}$ & $\mathrm{N}$ \\
\hline Pure PET & 72.5 & 28.8 & 0 \\
$30 \mathrm{~s}$ & 71.8 & 27.4 & 0.8 \\
$100 \mathrm{~s}$ & 74.8 & 25.2 & 0 \\
$200 \mathrm{~s}$ & 79.2 & 21.8 & 0 \\
$400 \mathrm{~s}$ & 81.8 & 18.2 & 0 \\
Pure PSMA & 90.6 & 9.4 & 0 \\
\hline
\end{tabular}
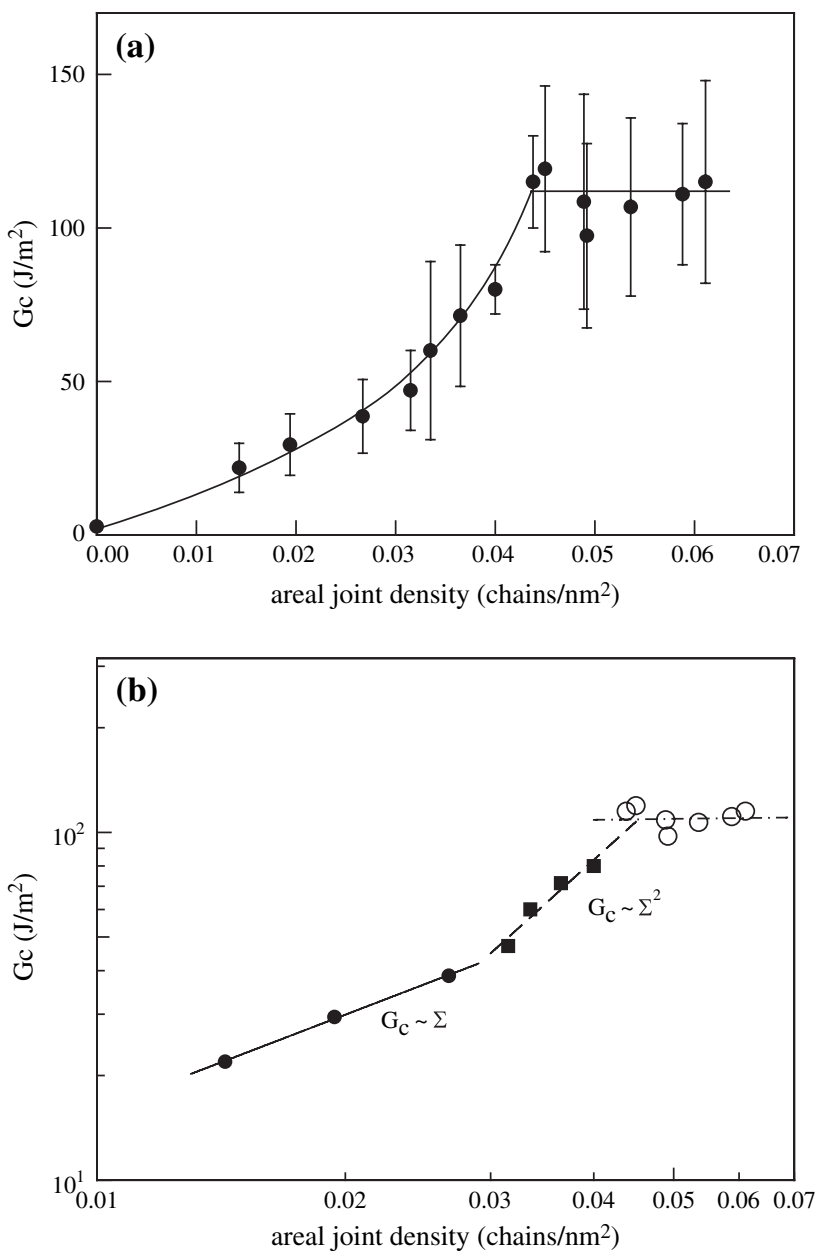

Fig. 9. (a) The fracture toughness, $G_{\mathrm{c}}$ of the interface heat treated at $150{ }^{\circ} \mathrm{C}$ as a function of areal joint density of the in situ formed copolymer at the interface. (b) The double logarithmic plot of the same $G_{\mathrm{c}}$ versus the areal joint density of the copolymer.

suggests that for the adhesive joints annealed at $160{ }^{\circ} \mathrm{C}$, more functional groups are generated on PET surface and react with maleic anhydride groups on the interface with increasing plasma treatment time. As the interfacial adhesion exceeds the cohesive strength of PSMA substrate, fracture near the PSMA/PET interface but inside PSMA substrate occurs. The cohesive strength of PSMA should be quite similar to that of a high molecular weight PS which is much larger than $50 \mathrm{~J} / \mathrm{m}^{2}$. Therefore, can the change in fracture toughness and failure location be affected by the way that PSMA reacts with functionalized PET film. In general, the adhesion of the interface depends on the number of in situ formed copolymers at the interface. However, since PSMA homopolymer has a large amount of (7 wt \%) maleic anhydride functional groups arranged randomly along the chain, each PSMA polymer can possibly make multiple chemical bonds with functionalized semicrystalline PET film surface. A schematic of a PSMA chain grafted on functionalized PET film surface is shown in Fig. 1(b). To elucidate this peculiar temperature dependence on the location of failure, analysis of fracture mechanisms is necessary. 


\subsection{Failure analysis}

In order to understand the correlation between the interfacial fracture toughness of PET/PSMA adhesive joints and the areal density of grafted PSMA chains on the plasmatreated PET film surface, analysis on both sides of the fracture surfaces of the PET/PSMA adhesive joint was done by using XPS measurements. Following the examination by Leger et al. [42], we use $\mathrm{N}$ 1s and $\mathrm{C}$ 1s signals on fracture surfaces obtained from XPS measurement to estimate the areal chain density, $\Sigma$ of in situ formed copolymers at the interface. We assume that any N 1s signal that appeared on the XPS spectra of the PSMA side of the fracture surfaces comes exclusively from functionalized PET chains grafted onto the surface of PSMA. The analysis is done on the fracture surfaces of the adhesive joints heat treated at $150{ }^{\circ} \mathrm{C}$ for $2 \mathrm{~h}$. The thickness $d$ of functionalized PET chains grafted on PSMA is related to normalized nitrogen signal (N/C) through Eq. (3).

$$
\frac{(\mathrm{N} / \mathrm{C})}{(\mathrm{N} / \mathrm{C})_{\infty}}=1-\exp \left(-\frac{d}{\Lambda}\right)
$$

where $(\mathrm{N} / \mathrm{C})_{\infty}$ is the normalized signal for a freshly plasmatreated PET film at the same plasma treatment time and $\Lambda$ accounts for the escape length of the electrons through the plasma-treated layer and is estimated to be $5 \mathrm{~nm}$. The areal chain density of the grafted PSMA can be expressed as follows:

$\Sigma_{\text {cross }}=-\frac{N_{\mathrm{a}} \rho \Lambda}{M_{\mathrm{n}}} \ln \left(1-\frac{(\mathrm{N} / \mathrm{C})}{(\mathrm{N} / \mathrm{C})_{\infty}}\right)$

where $N_{\mathrm{a}}, \rho$ and $M_{\mathrm{n}}$ are the Avogadro's number, density of PET $\left(\rho \approx 1.35 \mathrm{~g} / \mathrm{cm}^{3}\right)$, and the number-average molecular weight of PSMA $\left(M_{\mathrm{n}} \approx 100,000 \mathrm{~g} / \mathrm{mol}\right)$, respectively. Since each PSMA chain has an average of $7 \mathrm{wt} \%$ maleic anhydride and therefore can react with the plasma-treated PET film for multiple times, PSMA may form a stitch structure when it is reacted at the interface. On the basis of the stitch structure of the grafted PSMA chains at the interface we therefore define the areal density as the areal joint density, $\Sigma_{\text {cross }}$ which is the number density of the grafted PSMA excursions at the interface. Although, strictly speaking, the calculation of the areal chain density of grafted PSMA using Eq. (4) is incorrect; since we overestimate the areal joint density of the grafted PSMA by assuming that all nitrogen measured on the PSMA side of the fracture surface reacts with the maleic anhydride groups on PSMA. As an approximation, the areal joint density $\Sigma_{\text {cross }}$ is used as upper limit of the chain density of the copolymers and is used to correlate with the fracture energy measured by the ADCB method as well as the fracture mechanism [43].

In Fig. 9(a), the fracture toughness of the PET/PSMA interface is plotted as a function of areal joint density, $\Sigma_{\text {cross }}$ of in situ formed copolymers calculated based on Eq. (4). For $\Sigma_{\text {cross }}<0.045$ chains $/ \mathrm{nm}^{2}$, the fracture toughness of the interface increases with increasing $\Sigma_{\text {cross }}$ of the copolymers. For
$\Sigma_{\text {cross }}>0.045$ chains $/ \mathrm{nm}^{2}, G_{\mathrm{c}}$ becomes independent of the areal joint density. For samples with $\Sigma_{\text {cross }} \sim 0.045$ chains $/ \mathrm{nm}^{2}$, the treatment condition for the sample corresponds to a plasma treatment for $150 \mathrm{~s}$ and subsequent annealing of the adhesive joint at $150{ }^{\circ} \mathrm{C}$ for $2 \mathrm{~h}$. Based on the results from Fig. 8(a) and Table 1, the failure of the PET/PSMA adhesive joints plasma treated for $\geq 200 \mathrm{~s}$ occurs inside the PET layer. Therefore, $G_{\mathrm{c}}$ becomes independent of the areal joint density since the interfacial adhesion is now exceeding the bulk fracture toughness of PET film.

We can further understand the deformation mechanism of the PET/PSMA interface by replotting $G_{\mathrm{c}}$ versus $\Sigma_{\text {cross }}$ on a double logarithmic scale. As seen from Fig. 9(b), the areal joint density can be further divided into three regions: for $\Sigma_{\text {cross }}<\Sigma_{\text {cross }}^{*}=$ 0.03 chains $/ \mathrm{nm}^{2}$, all $G_{\mathrm{c}}$ values are small $\left(<40 \mathrm{~J} / \mathrm{m}^{2}\right)$ and $G_{\mathrm{c}}$ increases linearly with increasing $\Sigma_{\text {cross }}$; for 0.045 chains/ $\mathrm{nm}^{2}>\Sigma_{\text {cross }}>0.03$ chains $/ \mathrm{nm}^{2}, G_{\mathrm{c}}$ increases sharply with $\Sigma_{\text {cross }}$ and scales with $\Sigma_{\text {cross }}^{2}$; for $\Sigma_{\text {cross }}>0.045$ chains $/ \mathrm{nm}^{2}$, $G_{\text {c }}$ reaches a maximum value and is independent of $\Sigma_{\text {cross }}$.

For polymer interface reinforced with diblock copolymers, Creton et al. [6] have shown that there is a fracture transition from chain scission of diblock copolymer to crazing of a homopolymer with a transitional areal chain density, $\Sigma_{\mathrm{di}}^{*}$, of 0.03 chains $/ \mathrm{nm}^{2}$. Brown [44] and Kramer et al. [45] have experimentally and theoretically demonstrated the relationship of interface adhesion and areal chain density of connecting chains: if failure of the interface occurs by simple chain scission or chain pull-out without any extensive plastic deformation, then $G_{\mathrm{c}}$ is a linear function of $\Sigma$; if the applied stress at the interface is sufficient to activate bulk plastic deformation mechanisms, then $G_{\mathrm{c}}$ increases significantly and scales with $\Sigma^{2}$. Creton et al. [6] further demonstrated that the transitional areal chain density $\Sigma_{\mathrm{di}}^{*}$ from chain scission to crazing failure of an interface reinforced with a diblock copolymer can be used to estimate the force to break a single carbon-carbon bond of the copolymer at the interface provided that the crazing stress of the plastically deformed homopolymer is known.

In this study, we observed a similar $G_{\mathrm{c}}$ dependence versus areal density and approximately the same value of the areal density for the transition. Therefore, it is reasonable to speculate that for a similar failure transition from chain scission of the copolymer to plastic deformation occurs at the PS/PSMA reinforced with in situ formed copolymers. For plasma treatment time $<150 \mathrm{~s}$, since nitrogen signals are found on both sides of the fracture surface as shown in the XPS survey scan, the crack tip stress is high enough to generate plastic deformation of PET/PSMA interface and subsequently failure of the plastically deformed PET. Note that the areal joint density $\Sigma_{\text {cross }}$ is theoretically related to the areal chain density $\Sigma$ by the average number of grafting point $n$ of PSMA pinned on the PET film surface.

$\Sigma_{\text {cross }}=n \Sigma$

The number of grafting point of each PSMA chain on PET film surface gives an indication of the chain conformation of the PSMA pinned on PET surface. For example, if $n$ is 
relatively small, then the grafted PSMA chain may form a stitch structure with large enough loop to entangle with homopolymer PSMA. If, however, $n$ is large then the grafted PSMA chain forms many stitches with small loops and the loops may not be able to entangle well with PSMA homopolymer. In addition, since the value of $\Sigma_{\text {cross }}$ depends on $n$ and if $n$ is known, then the transitional areal density $\Sigma_{\text {cross }}^{*}=$ 0.03 chains $/ \mathrm{nm}^{2}$ in the current study can be used to estimate the force to break the in situ formed copolymer chain provided that the yield stress of the plastically deformed homopolymer is also known.

The dramatic change in the saturation fracture toughness and location of failure of the PET/PSMA adhesive joints with different heat treatment times and temperatures deserves much attention. Several kinetic theories of interfacial reaction of functional polymers have recently been proposed [46,47]. The grafting reaction is usually treated with two competing effects, namely reaction-controlled kinetics and diffusion-controlled kinetics that affect the chain conformation of in situ formed copolymer, fracture toughness and failure mechanism of the interface. The effect of heat treatment time on the saturation fracture toughness as shown in Fig. 5(b) can be understood based on the following argument. As more interfacial grafting reaction occurs, the fracture toughness increases. However, above a certain critical coverage of the grafted chains, further reactions are retarded since less functional group is left unreacted on the PET film surface and the diffusion of PSMA chains in the bulk through the already grafted layer is difficult because of the concentration gradient.

As shown in Fig. 5(b), the saturation $G_{\mathrm{c}}$ increases from $10 \mathrm{~J} / \mathrm{m}^{2}$ at $130{ }^{\circ} \mathrm{C}, 30 \mathrm{~J} / \mathrm{m}^{2}$ at $140{ }^{\circ} \mathrm{C}$, to $110 \mathrm{~J} / \mathrm{m}^{2}$ at $150{ }^{\circ} \mathrm{C}$. The growth rate in the saturation fracture toughness with increasing heat treatment temperature demonstrates that the grafting reaction is dominated by the reaction-controlled kinetics. Although at the heat treatment temperature $=150{ }^{\circ} \mathrm{C}$, bulk failure of PET film occurs. However, this result shows that the actual adhesion between the PET/PSMA interface at heat treatment temperature $=150{ }^{\circ} \mathrm{C}$ is even higher than $110 \mathrm{~J} / \mathrm{m}^{2}$. Therefore, at higher heat treatment temperature the possibility of diffusion-controlled process for adhesion enhancement is excluded.

For the PET/PSMA adhesive joints annealed at $160{ }^{\circ} \mathrm{C}$, the saturation fracture toughness decreases significantly to a value of $50 \mathrm{~J} / \mathrm{m}^{2}$ and the location of failure has drastically changed from a bulk failure of PET at $150{ }^{\circ} \mathrm{C}$ to a bulk failure of PSMA near the interface at $160{ }^{\circ} \mathrm{C}$. This result can be understood as follows: as PSMA chains react with functionalized PET film, the whole PSMA chain is pinned on the PET surface. With increasing heat treatment temperature, the grafted chains diffuse between grafted points, react with PET film and become more confined on the PET surface. Therefore, as the temperature increases, the grafted chains will have less entanglement with the bulk PSMA which becomes the weak link of the system and where the failure occurs. For an interface between propylene and Nylon 6 reinforced with ion beam irradiation, Kim et al. showed a similar effect of the bonding temperature on the saturation fracture toughness of the interface [14]. However, they observed a much higher temperature $\left(200{ }^{\circ} \mathrm{C}\right.$ in their study compared with $150{ }^{\circ} \mathrm{C}$ in the current study) at which the maximum fracture toughness is achieved. This difference in the heat treatment temperature to achieve the maximum adhesion is mainly due to the bulk failure of PET in our current study.

The failure mechanism and location of failure of PET/ PSMA interfaces reinforced with plasma treatment and subsequent different heat treatment temperatures are summarized. Fig. 10(a) and (b) shows a schematic representation of the chain conformation of PSMA grafted onto the functionalized PET surface for two different heat treatment temperatures. For heat treatment temperature $=150{ }^{\circ} \mathrm{C}$, the fracture toughness of the adhesive joints increases with increasing surface functionality of PET film as plasma treatment time increases. At this temperature, the average number of grafting point of PSMA chains near the interface is moderate. However, for

(a) bonding temperature at $150^{\circ} \mathrm{C}$

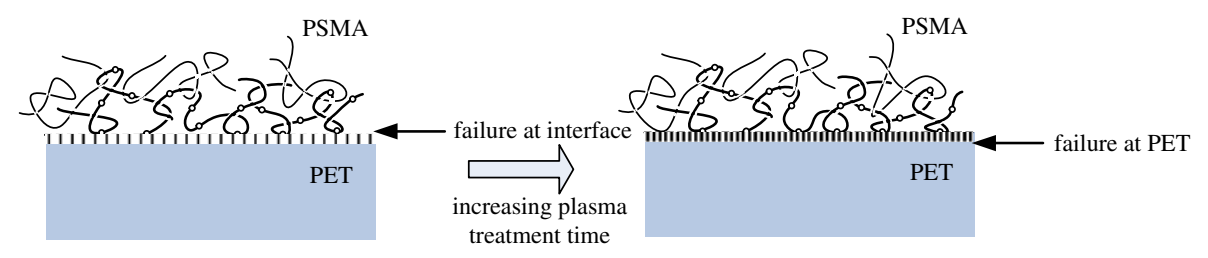

(b) bonding temperature at $160^{\circ} \mathrm{C}$

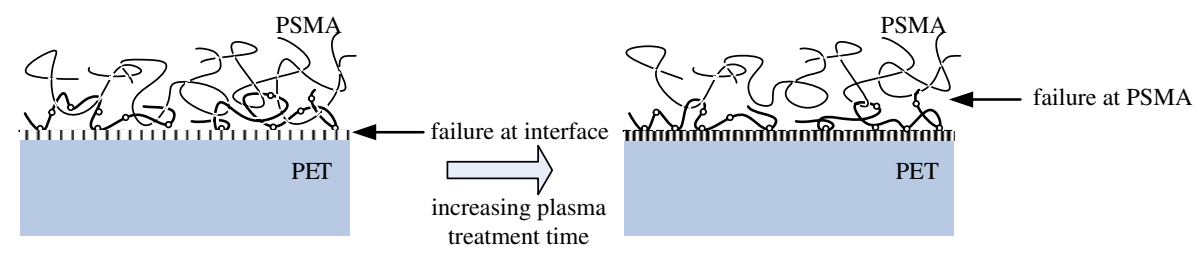

Fig. 10. Schematic representation of the formation of copolymers at the interface and location of failure with saturation in $G_{\mathrm{c}}$ at bonding temperature of (a) $150{ }^{\circ} \mathrm{C}$ and (b) $160^{\circ} \mathrm{C}$. 
heat treatment temperature $=160{ }^{\circ} \mathrm{C}$, the grafted chains are pinned on PET film surface and there are few entanglements between the grafted chains and the bulk homopolymer PSMA. Therefore, fracture occurs there.

\section{Conclusion}

In this study, the effects of chemical composition of nitrogen plasma-treated PET films and the bonding treatments between the treated PET and PSMA on their adhesion were investigated. The functional groups generated from the nitrogen plasma treatment of PET films are primarily in the form of amine and amide and the total amount of nitrogen incorporation increases with increasing treatment time and reaches a saturation value of $\sim 7.7 \%$. The fracture toughness and the failure mechanism of the interface between the plasma-treated PET films and PSMA substrates are greatly affected by plasma treatment time, post-plasma heat treatment time and temperature. The fracture mechanism map of PET/PSMA adhesive joint for different plasma and heat treatments was established by estimating the areal joint density, $\Sigma_{\text {cross }}$ of PSMA chains grafted on PET surface. Three failure regions were found for the adhesive joints annealed at $150^{\circ} \mathrm{C}$; for $\Sigma_{\text {cross }}<0.03$ chains $/ \mathrm{nm}^{2}$ failure of PSMA/PET interface by chain scission of in situ formed copolymers and $G_{\mathrm{c}}$ scales linearly with $\Sigma$; for $0.03<\Sigma_{\text {cross }}<0.045$ chains $/ \mathrm{nm}^{2}$ failure of the interface by plastic deformation and $G_{\mathrm{c}}$ scales linearly with $\Sigma_{\text {cross }}^{2}$; for $\Sigma_{\text {cross }}>0.045$ chains $/ \mathrm{nm}^{2}$, failure occurs in bulk PET film and $G_{\mathrm{c}}$ is independent of $\Sigma_{\text {cross }}$.

\section{Acknowledgement}

Financial supports from the National Science Council of Taiwan under contract number NSC92-2216-E-002-015 and NSC93-2120-M-002-010 are greatly appreciated.

\section{References}

[1] Liston EM, Martinu L, Wertheimer MR. J Adhes Sci Technol 1993;7: 1091

[2] Kalfoglou NK, Skafidas DS, Kallitsis JK. Polymer 1996;37:3387.

[3] Kampert WG, Sauer BB. Polymer 2001;42:8703.

[4] Lee S-S, Jeong HM, Jho JY, Ahn TO. Polymer 2000;41:1773.

[5] Creton C, Kramer EJ, Brown HR, Hui C-Y. Adv Polym Sci 2001;156:53.

[6] Creton C, Kramer EJ, Hui C-Y, Brown HR. Macromolecules 1992; 25:3075.

[7] Char K, Brown HR, Deline VR. Macromolecules 1993;26:4164.

[8] Majumdar B, Keskkula H, Paul DR. Polymer 1994;35:3164.

[9] Beck Tan NC, Peiffer DG, Briber RM. Macromolecules 1998;29:4969.
[10] Norton LJ, Smigolova V, Pralle MU, Hubenko A, Dai KH, Kramer EJ, et al. Macromolecules 1995;28:1999.

[11] Cho K, Li F. Macromolecules 1998;31:7495.

[12] Lee Y, Char K. Macromolecules 1994;27:2603.

[13] Lee Y, Char K. Macromolecules 1998;31(20):7091-4.

[14] Kim H-J, Lee K-J, Seo Y. Macromolecules 2002;35(4):1267-75.

[15] Fakirov S. Handbook of thermoplastic polyesters. Wiley-VCH; 2005.

[16] Werner E, Janocha S, Hopper M, MacKenzie KJ. Polyester, films. In: Kroschwitz JI, editor. Encyclopedia of polymer science and engineering, vol. 12; 1989. p. 193.

[17] Ajji A, Guevremont J, Cole KC, Dumoulin MM. Polymer 1996;37: 3707.

[18] Hastings GW. Cardiovascular biomaterials. London: Springer-Verlag; 1992.

[19] Ramires PA, Mirenghi L, Romano AR, Palumbo F, Nicolardi G. J Biomed Mater Res 2000;51(3):535-9.

[20] Sergent-Engelen T, Halleux C, Ferain E, Hanot H, Legras $R$, Schneider Y-J. Biotechnol Tech 1990;4:89.

[21] Pu FR, Williams RL, Markkula TK, Hunt JA. Biomaterials 2002;23: 2411.

[22] Gerenser LJ, Grace JM, Apai G, Thompson PM. Surf Interface Anal 2000;29:12.

[23] Yasuda H, Marsh HC, Brandt ES, Reilley CN. J Polym Sci Polym Chem Ed 1977;15:991.

[24] Briggs D. J Adhes 1982;13:287.

[25] Pochan JM, Gerenser LJ, Elman JF. Polymer 1986;27:1058.

[26] Collaud M, Groening P, Nowak S, Schlapbach L. J Adhes Sci Technol 1994;8:1115.

[27] Cohn D, Stern T. Macromolecules 2000;33(1):137-42.

[28] Shi MK, Dunham G, Gross ME, Graff GL, Marin PM. J Adhes Sci Technol 2000;14:1485.

[29] Scott C, Macosko CW. J Polym Sci Part B Polym Phys 1994;32:205.

[30] Gupta VB, Kumar S. J Appl Polym Sci 1981;26:1865.

[31] Bollen D, Deneir J, Aernoudt E. J Mater Sci 1989;24:2957.

[32] Lepers J-C, Favis BD, Kent SL. Polymer 2000;41:1937.

[33] Goschel U. Polymer 1995;36:1157.

[34] Marechal P, Coppens G, Legras R, Dekoninck J. J Polym Sci Part A Polym Chem 1995;33:757.

[35] Kanninen MF. Int J Fract 1973;9:83.

[36] Rice JR. Mathematical analysis in the mechanics of fracture. In: Liebowitz H, editor. Fracture - an advanced treatise, vol. 2; 1968. p. 191.

[37] Gerenser LJ. J Adhes Sci Technol 1987;1:303.

[39] Xiao F, Hui C-Y, Washiyama J, Kramer EJ. Macromolecules 1994; 27:4382.

[40] Sha Y, Hui CY, Kramer EJ, Hahn SF, Berglund CA. Macromolecules 1996;29(13):4728-36.

[41] Boucher E, Folkers JP, Hervet H, Leger L, Creton C. Macromolecules 1996;29:774.

[42] Boucher E, Folkers JP, Creton C, Hervet H, Leger L. Macromolecules 1997;30:2102.

[43] Dai C-A, Jandt KD, Iyengar DR, Slack NL, Dai KH, Davidson WB, et al Macromolecules 1997;30(3):549-60.

[44] Brown HR. Macromolecules 1991;24:2752.

[45] Hui C-Y, Ruina A, Creton C, Kramer EJ. Macromolecules 1992;25: 3948.

[46] Kramer EJ. Isr J Chem 1995;35:49.

[47] Fredrickson GH, Milner ST. Macromolecules 1996;29:7386. 